ШАПОШНИКОВ Александр Андреевич - аспирант Нижегородского государственного лингвистического университета им. Н.А. Добролюбова (603155, Россия, г. Нижний Новгород, ул. Минина, 31a; sv.ustinkin@gmail.com)

\title{
ЭФФЕКТИВНОСТЬ ДЕЯТЕЛЬНОСТИ ВНУТРЕННИХ ВОЙСК МВД ПО ОБЕСПЕЧЕНИЮ БЕЗОПАСНОСТИ РОССИИ ОТ ВНУТРЕННИХ УГРОЗ (1991-2016)
}

Аннотация. В статье анализируются проблемы эффективности деятельности внутренних войск в период с 1991 по 2016 г., т.е. с момента трансформации Внутренних войск СССР во Внутренние войска МВД РФ и до их реорганизации в Федеральную службу войск национальной гвардии Российской Федерации (Росгвардия). Уточняются критерии определения их действенности, доказывается достижение основных стратегических целей по обеспечению безопасности России от внутренних угроз.

Ключевые слова: внутренние войска МВД РФ, система обеспечения национальной безопасности, новые вызовы и угрозы, «цветные революции», «гибридная война», эффективность деятельности, критерии оценки внутренней безопасности

B опрос о эффективности деятельности Внутренних войск МВД РФ (ВВ МВД РФ) носит дискуссионный характер. В мировой историографии даются прямо противоположные оценки деятельности российских силовых структур, правоохранительных органов и военной организации государства в указанный исторический период ${ }^{1}$ [Манойло 2015]. Продолжается полемика по определению критериев эффективности в разных сферах национальной безопасности, во внешней и внутренней политике РФ [Аврутин 1998; Берекашвили 1981; Гончаренко, Куценко 2005; Белоконь, Коломоец 2017; Устинкин 2006; Устинкин, Рудакова, Морозова 2013; Савруцкая, Устинкин 2013]. Делаются попытки определения индексов эффективности политики обеспечения национальной безопасности и по количественным параметрам [Цырендоржиев 2014], и в форме аддитивной и мультипликативной сверстки частных показателей состояния конкретных видов безопасности в обобщающую оценку [Белоконь, Коломоец 2017]. Сложность определения эффективности деятельности ВВ МВД РФ заключается еще и в том, что ее результаты не всегда могут быть представлены в числовом выражении, а качественные оценки могут носить субъективный характер [Шапошников 2018].

Определение действенности реализуемой политики обеспечения национальной безопасности, деятельности правоохранительных органов и военной организации государства являлось важным этапом процесса принятия и реализации политических решений руководством страны, командованием ВВ МВД РФ. Оценка эффективности была связана с необходимостью выявления существенных факторов, влияющих на процесс обеспечения безопасности; корректировки избранного политического курса в связи с появлением новых вызовов и угроз личности, обществу и государству; совершенствования нормативно-правовой базы деятельности силовых структур; разработки алгоритмов реализации стандартных рациональных вариантов решений для всех силовых структур в условиях изменения ситуации внутри страны и на международной

\footnotetext{
1 Антони Рыбчиньский. Опричники Путина. Национальная Гвардия наращивает силы. Доступ: https://inosmi.ru/military/20170622/239652227.html (проверено 16.09.2018); Как реформировать силовые органы в России. - Новые известия. Доступ: https://newizv.ru/comment/pavel-luzin/07-02-2018/ kak-reformirovat-silovye-organy-v-rossii
} 
арене, своевременной постановки в связи с этими изменениями основных целей и задач деятельности ВВ МВД РФ; анализа возможностей по ресурсному обеспечению военной и внутренней безопасности; анализа прогнозных сценариев обострения напряженности и усиления разного рода конфликтов, динамики военно-политической обстановки в разных регионах страны; определения параметров облика правоохранительных органов и военной организации государства, в т.ч. ВВ МВД РФ, для каждого сценария обеспечения национальной безопасности и реализации национальных интересов на прогнозируемый период; осуществления контроля за реализацией политики обеспечения безопасности во всех сферах общественной жизни; моделирования исходов операций по обеспечению безопасности и поддержанию режима чрезвычайного положения (ЧП) и контртеррористических операций; оценки полученных результатов в соответствии с поставленными стратегическими и тактическими целями и задачами по защите России от внутренних, трансграничных и внешних угроз. Все вышеперечисленные действия органов власти, госуправления, политического руководства страны, командования силовых структур, правоохранительных органов и военной организации государства, представителей элитарных групп, институтов гражданского общества были достаточно четко скоординированы и конкретизированы по задачам, стоящим перед соответствующими ведомствами, организациями и институтами и во всей своей совокупности при их реализации могут, на наш взгляд, являться критериями оценки эффективности деятельности ВВ МВД РФ в исследуемый исторический период. Эффективность деятельности ВВ МВД РФ следует оценивать на всех этапах процесса принятия и реализации как политических решений руководства страны, так и решений командования соответствующих структур и подразделений внутренних войск, являвшихся, как известно, главной ударной силой МВД и составной частью военной организации государства.

Рассмотрим подробнее наиболее существенные элементы процесса оценки действенности правоохранительных органов и военной организации при защите государственности России от внутренних угроз.

1. Стратегия национальной безопасности РФ определяет, что контроль за ходом ее реализации осуществляется в рамках государственного мониторинга состояния национальной безопасности 1 . Порядок оценки состояния национальной безопасности регламентируется Положением об оценке и государственном мониторинге состояния национальной безопасности РФ². Результаты мониторинга отражаются в докладах секретаря Совета безопасности президенту РФ. В ходе мониторинга учитываются более 60 критериев и показателей национальной безопасности. При этом понятие «внутренняя безопасность» в качестве отдельного вида не выделяется. На наш взгляд, это затрудняет процесс определения всего спектра существующих и прогнозируемых угроз в этой сфере. Правда, в Концепции национальной безопасности РФ используется термин «внутриполитическая сфера национальных интересов России», которая с точки зрения обеспечения политики внутренней безопасности личности, общества и государства включает в себя следующие элементы: «сохранение стабильности конституционного строя, институтов государственной власти, обеспечение гражданского мира и национального согласия, территориальной целостности, единства правового пространства,

\footnotetext{
1 Указ Президента РФ от 31.12.2015 № 683. «О стратегии национальной безопасности РФ». $-C 3$ РФ. 2016. № 1. Ч. II. Ст. 212.

2 Указ Президента РФ от 31.12.2015 № 684 «Об оценке государственного мониторинга состояния национальной безопасности».
} 
правопорядка, а также нейтрализацию причин и условий, способствующих возникновению политического и религиозного экстремизма, этносепаратизма и их последствий - социальных, межэтнических, религиозных конфликтов и терроризма» 1 .

В Положении об оценке национальной безопасности в качестве основных нормативно закреплены следующие показатели, имеющие непосредственное отношение к обеспечению национальной безопасности РФ: удовлетворенность граждан степенью защищенности своих конституционных прав и свобод, личных и имущественных интересов, в т.ч. от преступных посягательств; доля современных образцов вооружения, военной и специальной техники в Вооруженных силах Российской Федерации, других войсках, воинских формированиях и органах; ожидаемая продолжительность жизни; валовой внутренний продукт на душу населения; децильный коэффициент; уровень инфляции и безработицы; доля расходов в бюджете на развитие науки, технологий, образования, культуры; доля территории РФ, не соответствующая критериям экологической безопасности ${ }^{2}$. Остальные критерии Положения об оценке национальной безопасности утверждены по предложению соответствующих министерств и ведомств по всем сферам общественной жизни, а также по рекомендациям научного совета при Совете безопасности РФ. Совершенствование законодательства, нормативно-правовой базы СОНБ, деятельности преемника ВВ - ФС ВНГ (Росгвардия) - задача, стоящая перед руководством страны и руководителями всех силовых структур.

2. Поскольку в мире в настоящее время практика свержения легитимных политических режимов, провоцирование внутригосударственной нестабильности получает все большее распространение, а современные войны, в т.ч внутренние вооруженные конфликты, носят «гибридный» характер, составной частью которых являются «цветные революции», кибератаки, подготовительные мероприятия в формате «мягкой силы», а ответ на них с применением обычных войск часто невозможен, противодействовать этим новым угрозам необходимо также «гибридными» методами. Внутренние войска МВД РФ были предназначены для ответа на часть этих вызовов в условиях практически полного стирания границ между временем войны и мира в ряде регионов РФ. Разумеется, ВВ МВД РФ не являлись универсальным средством защиты от всех и всяческих внутренних угроз. В законе РФ «О внутренних войсках МВД РФ» от 24 сентября 1992 г. декларировалось, что внутренние войска являются воинскими формированиями, объединением, существующим в структуре МВД РФ и выполняющим задачи «по обеспечению внутренней безопасности государства, общественной безопасности, защиты прав и свобод человека от преступных и иных противоправных посягательств, а также четко сформулированы основные цели, задачи и направления их деятельности» ${ }^{3}$.

В указе Президента «О Стратегии национальной безопасности РФ» были уточнены наиболее опасные внутренние угрозы безопасности $\mathrm{P} \Phi^{4}$.

В любом социальном организме всегда существуют противоречия, являющиеся, с одной стороны, угрозой дестабилизации существующего полити-

1 Указ Президента РФ от 10.01.2000 № 24 «Концепция национальной безопасности РФ». - СЗ РФ. 1998. № 52, ст. 5909; 2000. № 2. Ст. 170.

2 Указ Президента РФ от 31.12.2015 г. № 683 «О стратегии национальной безопасности РФ». - СЗ РФ. 2016. № 1. Ч. VI. Ст. 115.

3 Федеральный закон «О внутренних войсках МВД РФ» от 06.02.1997 № 27-Ф3. - СЗ РФ. 10.02.1997. № 6. Ст. 711.

4 Указ Президента РФ «О стратегии национальной безопасности РФ» от 31.12.2015 № 683. - Сз РФ. 2016. 
ческого режима, с другой - источником развития общества. Задача власти, лидеров политических партий, элитных групп - научиться разрешать эти противоречия, своевременно проводить реформы в интересах большинства, не отказывая меньшинству в праве и возможности выражать и защищать свои интересы конвенциональными способами. Обеспечение в РФ принципа социальной справедливости, неукоснительного соблюдения провозглашенных в Конституции прав и свобод, преодоление раскола нации, обеспечение единства народа и власти являются важнейшими условиями обеспечения внутренней безопасности, при реализации которых любое вмешательство извне во внутренние процессы РФ не будет эффективным. И наоборот, утрата единства российским обществом, подрыв социально-политической стабильности, межнационального согласия и религиозной терпимости создадут объективные предпосылки для возможного разжигания извне разного рода конфликтов. При этом наличие в стране национально ориентированной и лояльной главе государства политической элиты, особенно «силовой», является еще одним из ключевых факторов успешного противодействия инициируемой при помощи технологий «гибридной войны» политической дестабилизации.

По каким же критериям можно оценивать эффективность деятельности ВВ МВД РФ в исследуемый период?

Как известно, под эффективной деятельностью понимается соответствие полученных результатов поставленным целям и задачам. Все основные поставленные перед ВВ МВД цели были реализованы.

В военно-политической сфере:

- защищены суверенитет и территориальная целостность РФ на Северном Кавказе;

- отражены попытки насильственного свержения конституционного строя, пресечены сепаратистские тенденции в Чеченской республике, Ингушетии и Дагестане;

- выполнены служебно-боевые задачи по стабилизации обстановки в Южном федеральном округе, в Республике Дагестан, в Карачаево-Черкесской Республике, Краснодарском крае;

- были разгромлены незаконные вооруженные формирования, успешно локализованы и блокированы районы чрезвычайного положения, пресечены внутренние вооруженные конфликты;

- осуществлена реализация комплекса оперативно-поисковых и разведывательных мероприятий по выявлению и нейтрализации лидеров и участников бандформирований (по оценке генерал-полковника Н.Е. Рогожкина, 90\% результативности деятельности группировки ВВ в Чечне обеспечили действия подразделений разведки и спецназа);

- осуществлялся поиск и ликвидация тайников с оружием и боеприпасами, подрывной литературой и т.д.;

- совместно с пограничной службой ФСБ усилена охрана государственной границы;

- в целях пресечения экстремистской и террористической деятельности, диверсионных актов проводились специальные точечные мероприятия и адресные проверки, велся поиск объектов и незаконных вооруженных формирований в заданных районах;

- осуществлялась защита коммуникаций, транспортной системы и инфраструктуры жизнеобеспечения в ходе проводимых мероприятий по противодействию диверсионно-террористическим актам и «минной войне»;

- моторизированные части ВВ МВД участвовали в охране общественного 
порядка в крупных городах, обеспечивали безопасность граждан при проведении массовых мероприятий;

- успешно осуществляли охрану важных государственных объектов.

B сфере военного строительства достижение поставленных целей потребовало реформирования ВВ МВД для приведения их соответствие с решаемыми задачами обеспечения внутренней безопасности:

- ВВ превратились в высокоэффективные, мобильные, профессионально обученные и оснащенные войска;

- их структура, состав и численность были приведены в соответствие с внешними и внутренними условиями развития государства;

- В 2006-2008 гг. была организационно оптимизирована штатная структура на основе преобразования органов военного управления, уточнены структура и состав воинских частей оперативного и специального назначения, специальных моторизированных частей и других подразделений;

- в 2009-2010 гг. была сформирована оптимальная группировка войск, способная адекватно реагировать на внутренние угрозы РФ;

- управления округов ВВ были преобразованы в региональные командования;

- в целях повышения мобильности и управляемости ВВ военные части оперативного назначения были переведены на бригадную основу;

- ВВ избавились от тяжелого вооружения, передав его в Вооруженные силы РФ, получив взамен новые виды вооружения и специальной техники, в т.ч. боеприпасы нелетального действия, приборы по обнаружению, наблюдению, разведке различных целей в комплексе со средствами их подавления и уничтожения;

- совершенствовалась организационная структура подразделений ВВ;

- был приобретен бесценный боевой опыт ведения боевых действий в горнолесной местности, в условиях большого города, апробированы новые технологии и средства, формы и методы вооруженной борьбы.

Разумеется, это произошло не сразу - за приобретение опыта, тем более в боевых условиях, как известно, приходится расплачиваться людскими, материальными, нравственными потерями.

В Чеченской республике (1994-1996 гг.) военные формирования, части и подразделения, принимавшие участие в боевых действиях, потеряли убитыми и умершими 5552 чел., в т.ч. пропавшими без вести и попавшими в плен - 510 чел. Из них потери ВВ МВД РФ составили: 197 офицеров, 55 прапорщиков, 266 сержантов, 1033 рядовых - всего 1551 чел. [Кривошеев и др. 2010: 602]. В ходе контртеррористической операции на Северном Кавказе в 1999-2000 гг. потери составили 3007 чел. [Кривошеев и др. 2010: 612]. Память о погибших увековечена в мемориальных комплексах, памятниках, обелисках, специальной Книге памяти. 80 военнослужащих, совершивших героические подвиги при разрешении вооруженного конфликта на территории Чеченской республики, навечно зачислены в списки своих воинских частей; 70 военнослужащих ВВ МВД РФ удостоены звания Героя России, 47 из них - посмертно.

В соииально-политической сфере и сфере этноконфессиональных отношений:

- осуществлена ликвидация очага сепаратизма, экстремизма, террористической и разведывательно-диверсионной деятельности, которая дала возможность стабилизировать общественно-политическую обстановку не только в регионе, но и на территории всей РФ;

- на Северном Кавказе начался процесс восстановления народного хозяйства, строительства жилья; 
- был приобретен бесценный опыт использования «мягкой силы» в разрешении этноконфессиональных конфликтов;

- была снижена социальная напряженность;

- развернута работа с национальными элитами, духовенством, интеллигенцией, молодежью, что привело к значительному снижению рисков перерастания напряженности во внутренние, в т.ч. вооруженные, конфликты, т.е. обеспечено сохранение стабильности конституционного строя, институтов государственной власти, восстановлены гражданский мир и национальное согласие, территориальная целостность, единство правового пространства и правопорядка в РФ.

Разумеется, опыт неукоснительного соблюдения прав человека и гражданина, гарантированных Конституцией РФ и международными организациями, при подавлении массовых беспорядков в условиях обеспечения режима контртеррористической деятельности нуждается в осмыслении, развитии и непрерывном совершенствовании преемником ВВ МВД РФ - Росгвардией. То же относится к противоборству в информационном пространстве, которое со стороны федеральных сил не всегда было эффективным.

Таким образом, были достигнуты основные стратегические и тактические цели, поставленные перед ВВ МВД РФ:

- извлечены уроки из совершенных просчетов и ошибок;

- обобщен и развит полученный опыт защиты национальной безопасности от внутренних угроз;

- осуществлено совершенствование организационной структуры и деятельности правоохранительных органов и военной организации государства;

- ВВ были обеспечены современными образцами вооружения и техники;

- проведено совершенствование социальной защиты военнослужащих;

- поднят авторитет ВВ в общественном сознании.

И все это осуществлено при приемлемом уровне государственных затрат и издержек, безвозвратных человеческих потерь, что позволяет высоко оценить эффективность деятельности ВВ МВД РФ по обеспечению национальной безопасности от внутренних угроз.

\section{Список литературы}

Аврутин Ю.Е. 1998. Оценка эффективности деятельности органов внутренних дел (опыт системного исследования). СПб: Санкт-Петербургская академия МИД России. 470 с.

Белоконь С.П., Коломоец О.В. 2017. Научно-методические проблемы оценивания национальной и военной безопасности Российской Федерации. Вестник Академии военных наук. № 4(61). С. 4-18.

Берекашвили Л.Ш. 1981. Проблемы оценки эффективности деятельности органов внутренних дел. М.: Академия МВД СССР. 136 с.

Гончаренко Л.П., Куценко Е.С. 2005. Управление безопасностью: учебное пособие. М.: КноРус. 272 с.

Кривошеев Г.Ф., Андронников М.М., Пуриков П.Д. и др. 2010. Россия и СССР в войнах ХХ века. Книга потерь. М.: Вече. 624 с.

Манойло А.В. 2015. Гибридные войны и цветные революции в мировой политике. - Право и политика. № 7. С. 918-929.

Савруцкая Е.П., Устинкин С.В. 2013. К вопросу о необходимости повышения эффективности миграционной политики в России. - Власть. № 9. С. 39-44.

Устинкин С.В. 2006. К вопросу о критериях эффективности государственной молодежной политики. - Проблемы обновления России: материалы IV Международной конференции. 27 апреля 2006 г. Н. Новгород. С. 149-159. 
Устинкин С.В., Рудакова Е.К., Морозова Н.М. 2013. Оценка эффективности этнонациональной политики России. - Власть. № 9. С. 10-15.

Цырендоржиев С.Р. 2014. О количественной оценке степени военной безопасности. - Военная мысль. № 10. С. 27-40.

Шапошников А.А. 2018. Проблемы изучения внутренних войск РСФСРСССР-РФ (1918-2018 гг.). - Власть. № 7. С. 211-2015.

SHAPOSHNIKOV Aleksandr Andreevich, postgraduate student of Dobroljubov State Linguistics University of Nizhny Novgorod (31a Minina St, Nizhny Novgorod, Russia, 603155; sv.ustinkin@gmail.com)

\section{EFFICIENCY OF ACTIVITIES OF INTERNAL TROOPS OF THE MINISTRY OF INTERNAL AFFAIRS FOR SAFETY OF RUSSIA FROM INTERNAL THREATS (1991-2016)}

\footnotetext{
Abstract. The article analyzes problems of efficiency of activity of internal troops during the period from 1991 to 2016, from the moment of transformation of internal troops of the USSR in internal troops of the Ministry of Internal Affairs of the Russian Federation, and before their reorganization in Federal National Guard Troops Service of the Russian Federation (Rosgvardiya). The author specifies the criteria for determining their effectiveness, and proves the achievement of the main strategic objectives for ensuring security of Russia from internal threats.

Keywords: internal troops of Ministry of Internal Affairs of Russian Federation, system of ensuring national security, new challenges and threats, color revolutions, hybrid war, efficiency of activity, criteria for evaluation of internal security
} 